\title{
Polygon peace theory: initiating and leading inter- cultural peace dialogue in Rwenzori region for peace building strategy
}

\begin{abstract}
This article presents the argument that polygon peace theory is model that provides a platform which silently engages parents and children into peaceful settlement of conflicts and fostering co-existence without biasness caused by selfish politicians. The horrific massacre that have occurred in Rwenzori since $1250 \mathrm{AD}$ in most cases have gone without causing public attention on front pages of news papers and headlines in national and international media houses. It seems in this $21^{\text {th }}$ Century some people still don't deserve equal human rights as to "them" whose human rights are protected by international laws. The human rights violation has not occurred in Rwenzori but also in other parts of the world with less recognized human rights. The "mystic rose problem" that have caused episodic conflicts can still get solution through applying polygon peace theory as identification of one side of the polygon can be measured to find its length. This opinion is based on lived experience and desk research of the author.
\end{abstract}

Keywords: polygon peace theory, grievous theory, greedy theory, and inter-cultural dialogue
Volume 2 Issue 6 - 2018

\author{
Moses Muhindo Kibalirwandi \\ Mbarara University of Science and Technology, Uganda
}

Correspondence: Moses Muhindo Kibalirwandi, Mbarara University of Science and Technology, Uganda, Email kibalmoses@gmail.com

Received: January 23, 2018 | Published: December 20, 2018
Abbreviations: RHU, rwenzururu heritage university project; OBR, means Obusinga Bwa Rwenzururu; RDC, Resident District Commissioner (Representing the President of Uganda); MP, member of parliament elected by communities

\section{Introduction}

The polygon peace theory, advocate for employing scientific measurement of some identified length of sides or complex segments of the whole cause of conflicts that have rendered particular regions prone to episodic or continuous conflicts over centuries. Involving affect communities in inter-cultural dialogue and providing avenues to respect social identities and entitlements or public benefits in political, economic and social welfare leading improved livelihood is paramount in restoring peace and sanity. If life is not respected then it is not worth lived hence a struggle to make it meaningful or destroying it may be the alternative. The horrific massacre in Rwenzori where more than 200 people; babies, youth, adults men and women have mercilessly been killed within a period between July 2014 to March 2017 and detaining others in criminals prisons has not awakened the global on dangers of conflicts and failure to accept globalization as a need for humanity. Rwenzori region has got about 14 sub-ethnic cultural groups that have lived together for more than one century. Bakonzo/ Banande, Bamba, Batoro, Banyabindi, Batagwenda, Bakingwa, Batalinge, Bahema, Nyamulenge, Bahima and others have got common life challenges of low access to education hence raided by ignorance and little exposure to global issues and benefits like electricity, internet, information and trade. Education provision and public goods like roads and other basic needs of life are ideally inaccessible.

\section{Examining the cultural background of the Rwenzori community as perceived}

Being aware that culture includes knowledge, belief, art, law, morals, customs and other capabilities, I do not want to risk myself in defining each of the concepts associated and within the definition of culture listed here. If I would define each of the concepts, then it may result into writing volumes on each and take time that is not accorded to me. In brief culture is built after a long period of time and knowledge is shared hence culture is created and is a result of interactions among community members. In the event where community members (traditional teachers) fail somewhere to do "right", then wrong doing may be perpetuated among the community. Negativity towards government programme that is evident in Rwenzori may be due to the culture of resentment that has grown due to long suffering inherited in the region as conflicts have overruled the region. Rwenzori region is having its own culture that currently appear complex yet understandable to the scholars since it has been constructed during time of fear and tyranny nearly seven hundred sixty years marked from 1250 AD Bakonzo have lived in time of turmoil. ${ }^{1}$ The period between from 1833 to $1921 \mathrm{AD}$ is marked as $1^{\text {st }}$ establishment of Toro kingdom in Rwenzori. Toro Kingdom overruled Bakonzo and Bamba by force making them slaves in their motherland. The Toro Kingdom under the leadership of Kaboyo son of kyabambe Nyamutukura was created in the region and Whites (British colonialists) supported the suppression of the Bakonzo hence creating the worst society of conflict much as this contributed to the history and culture of the community in Rwenzori. A number of lessons can be drawn from sectarian leadership of divide and rule approach within related communities. The suppressed Bakonzo/Bamba with other Minority community members of Banyabindi created a rebellion resisting hegemony and made Bakonzo-Bamba Life History Research that gave birth to; the creation of Rwenzururu Movement and Separate Districts of Kasese and Bundibugyo agitation. ${ }^{1}$ Entitlements like medical, education; employment and recognition constitutionally have gradually been achieved in the region. The community is still hungry of entitlements like land recovery or compensation, establishing development projects and initiating employment opportunities. The separate districts remained in chaos due to the Rwenzururu Movement and defectors to the struggle. Demonization and misrepresentation 
overruled the region hence conflicts were groomed to brood hatred among the local communities. Ideologies to join this disgruntled community were formulated as a means of charismatic spirit to orient the community for rebellion. Ignorance was fronted in many instances that fabrications overruled the thinking of many individuals hence misrepresentation. ${ }^{2}$ Basing upon the above background in brief, promoters of Rwenzururu Heritage University project thought of inventing modern ideologies to orient the community. The struggle has been made to get funds and land of about 20 acres that all require about 78 billion Uganda shillings. This idea has not be seen important yet only one year's revenue collected from a factory in the region out of many can provide for this noble cost. Hiima Cement factory pays 54 billion Uganda shillings annually to the country. This is one factory or company within the region.

The cultural transformation is ideological hence education institutions are vanguards in socialization process that provides curriculum which transforms the learners. New ideologies stated as opposed to those like marginalization, uncompensated demands, sense of oppression, less considered for entitlements and many others that leads to fabrication of separate state (YIRA STATE)need to be addressed through counter attack ideologies and concepts to orient the community into a global realities of development, mobility of labour, global education view, and citizenship education. The existing culture has taken more than 767 years and all along it has been time of strive and agony! The Rwenzori community that is ever in tears because of clashes that have taken cycles of short periods of peace and again clashes, displacement, resulting into loss of lives and property request for your contribution and rehabilitation. Such episodes, victims of circumstances (community) do not need retributive but sympathy and rehabilitation! It has remained a question to identify the enemy in the Rwenzori communities which is not yet answered and we anticipate that this question will be answered by research. As the above is examined, a "mystic rose" kind of problem is associated with peace and stability in Rwenzori region. Hanrahan et al., ${ }^{3}$ arguable states, "problem solving is an essential part of mathematics. In order to solve problems you need to know the language with which to express the work you are doing". A mystic rose has 18 points yet the simplest mystic rose can be a polygon. This gives a solution as N=1/2.P (P-1) on assumption that $\mathrm{P}$ is real positive number. This approach identifies lines that network the "mystic rose". Buchana \& Gaulter ${ }^{4}$ apply sines and cosines if sides of any polygon are known. This explains that all segments that give rise to the conflicts in Rwenzori are well known to its community and solutions can easily be found, it is not a mystic rose but a polygon with clear lines of defined length. It does not matter if one side length of a polygon is known an exterior angle will be thought of and a solution to the problem will be got without dismantling the polygon. The community love their cultural institution and willing to support it as their "own baby"!

\section{Self-image as a source of conflict in the region}

The perceived "Marginalization of the Bakonzo community" is a myth or a reality in the Rwenzori region hence a lot of speculation. The ideological elusiveness carried in the modern world over marginalization has been shared and indoctrinated the children, youth and adults without justified explanation. The Land issue in courts of law and unresolved conflicts concerning land between local communities force third parties also assume the effect of marginalization in the area is yet an issue of ideology. The corruption at district level in terms of employment opportunity is mistakenly taken as grand marginalization by the actors molesting job seekers and tarnishing the image of central government leaders. Marginalization is politicized, magnified, and used as a tool to mislead the youth and general community by partisan politicians at different levels. The seed of hatred was planted by community members and it will be uprooted by the same community members because it is in the thicket hence anyone outside Rwenzori community may not uproot the seed rather scattering its seeds in the bush and allowing more to sprout and more hatred brooded. The "earth scotch policy" may not work because other community members will innocently die and the world will see no sense in the application of hostility. Educational platforms may contribute in addressing and explaining the "mystical" covered as marginalization which ends up resulting as fuel to regional conflicts. The University project was sought of as one of the platforms for researchers to conduct research and interact with learners, community both local and global to provide researched information which is unbiased.

The argument here is that we anticipate the university to employee about three hundred people (300 workers), train local community and International community hence attracting income in the area to overcome poverty and reduce unemployment. It will engage the community into productive activities and shift the attention from unproductive ventures. This intervention may contribute towards vision 2040 for Uganda in preparation of vision 2063 for African States. The author looks at policy formulation, implementation and monitoring practices in developing countries to be no different from target setting by impulse without involving affected communities. This ends at conference level hence jokes by misleaders. The few have used platforms to achieve selfish ends hence increasing poverty in most developing countries.

\section{Cognitive attempt for ideological change}

While the community in Rwenzori has survived m. ${ }^{1,2,5}$ The Ssembeguya and Lubbowa commission of 1950s, the Kajura Report on cultural issues about Omusinga Charles Wesley Irema-Ngoma and the restoration of cultural institution is well documented for reference. These have ideally provided insights into the sources of conflicts in the region. The same documents have shown that community immediate issues may have a solution when central government act and respond to community outcry. The establishment of the cultural institution (OBR) raised many questions yet some other cultural institutions restored or established in the Rwenzori region took different realities. There is no neutral politician who has justified the reasons for such a long process taken for the restoration of Obusinga Bwa Rwenzururu yet it was necessary and right for such complicated process basing on the historical background of the cultural institution (Obusinga Bwa Rwenzururu).The current leadership cannot assume that the community will take natural means to understand the secrete that was behind the delay of recognition of Obusinga Bwa Rwenzururu. This will only be explained by researchers who are not partisan politicians within academic institutions at conferences and academic platforms. It can still be discussed during talk show series that require buying airtime and facilitating participants to the talk show which is scholarly and in local languages.

The University library will collect relevant books, articles, and documentations into the archives so that as students will write term papers, research, and presentation locally and internationally will be valid other than basing on speculations. The ideologies planted within the Rwenzori communities resulting in aggressiveness and violence that result into poor community livelihood, poverty, loss of lives and general social unrest among others can only be solved by counteracting 
ideologies that expose the unworthiness of previous ideologies held by the communities. The situation of uncertainty within Rwenzori region as well as the country at large demand government's intervention to promote research and inter-cultural dialogue into community and national matters of concern. What about if it is the state or government causing panic? What would Jefferson say about the rule of law? The constitution should be for the country not the state and its operatives. The government and criminals can cause suffering and lose of peace but the constitution if it is for the people and by the people peace can be restored. The youth and all nationals can learn to restore peace and sanity in the country during school time or as they access education.

\section{Justification for establishing Rwenzururu heritage university}

There is no local university within the region which can meet the needs of the local community basing on their income level. The community felt establishing their own university project with affordable tuition fees so as to answer the long waited demands that gave rise to the establishment of the Rwenzururu Freedom struggle led by Isaaya Mukirania Kibanzanga I. The conflicts have yet made this effort futile as insecurity and poor governance has always manifested its nature. It is on record that President General Yoweri Kaguta Museveni is a champion of scientific transformation of this country (Uganda) through popular access to university education, modernization of agriculture, value added to agriculture produce, social transformation that encourage co-existence and many other issues. His patriotism and inspirations even made the promoters to design one proposed block for Agri-business faculty to be Named after Yoweri Kaguta Museveni to keep in memory for the next generation see page 37 of RHU campus plan in Strategic plan 2015-2020. Rwenzori region is a natural science laboratory for studies hence Agriculture, Environmental Management Science and Technology were proposed as key faculty to start with. This will help tourism, environmental management, agriculture, technology and research to benefit the local and global community hence a new change image for the local community.

Education institutions being agents of socialization, Rwenzururu Heritage University may be a center for socialization for different communities since Kasese is cosmopolitan district that has got more than 14 tribes or communities living together (Kasese District, 2009). The argument is that given opportunity and support to establish this university project the community members in Kasese will have been given start-up kit for image change into national community. In fact University education is an affirmative action to the Rwenzori community since they have remained backward for long as evidenced in their way of doing things that seem not modern.

\section{Reason for naming the university project as Rwenzururu heritage university}

Demand for education service in Rwenzori was observed as key issue in the establishment of "Rwenzururu Freedom Struggle" and rebellion against the Toro Kingdom hegemony. Education being key issue to bring all Bakonzo on board it was thought to use Rwenzururu Heritage University as "a catch-fish" for Bakonzo to join again and enjoy their participation in central government projects. The word Rwenzururu is enshrined in the culture of Bakonzo/Banande hence any diversion from it causes or opens wounds in the hearts of the inflicted remnants of the hegemony. The motion to change the name has been rejected twice in Board of trustees meeting hence for the three years the name has been maintained to remain Rwenzururu Heritage University. The Mountain of the Moon was originally known as snowcapped mountain Rwenzururu "Orusozi Rwe Nzururu" Nzururu means snow hence people love the Name Rwenzururu despite other stories surrounding the Name Rwenzururu. Some community members who came up with the idea of establishing the University opted for the Name which will remind the community about the beauty of protecting the snow on Rwenzori which is an environmental science issue for global attention without attributing to it basically to the Rwenzururu movement struggle of Isaaya Mukirania. A lot of disagreement has raised on changing the name hence project administrators have maintained the name and allowing natural pace to change or maintain it as it is now!

On the other hand the promoters thought of University to attract all supporters of Obusinga Bwa Rwenzururu and requested the King to support the community members' initiatives to gain respect and take some short courses that may help in changing some held ideologies, give a new orientation of the community into development and equipping human resource with skills to improved community livelihood. The community immediately started supporting the University which is having balanced promoters and administrative managers. The list of administrative management and promoters will be attached as special attachment on this document.

Finally, the Philosophy, vision, and mission of the university project and its proposed core course programmes provides evidence that it will be one of the local established Universities in Kasese and it will supplement the effort and ideas of Central Government in promoting development in the region.

\section{Proposed actors/strategies in resolving conflicts in the Rwenzori region}

Engaging the affected communities of Bakonzo, Bamba, Batoro, Basongora, Batagwenda, Bachingwe, Banyabindi, Bafumbiraand other small communities within Kasese may equally benefit as they sending their children in this University and they will socialize together hence reducing negativity among the communities. Researchers from local and international research institutes will interact and increase chances of employment and labor mobility. These researchers will interact with local communities hence co-existence and development will be enhanced in the region. Conflicts resolution experts have encouraged involvement of affected communities to work out solutions to end conflicts. In Rwenzori the biggest conflict was between Bakonzo and Batoro who are now marrying one another, giving scholarship and bursaries to Bakonzo as an indication of reconciliation and peaceful means of ending conflicts. After all confusion, it has come clear that colonialists and central government were very much responsible for fueling the conflicts in Rwenzori region basing on their approach which was biased as they marginalized Bakonzo/Bamba community and promoted other communities as if Bakonzo/Bamba were "subhumans".

The promoters are competent enough to use academic platform in order to be part of the Rwenzori peace recovery and development plan (RPRDP) which will tackle root causes of conflicts in Rwenzori and mitigate further conflicts and encourage citizenship education that is global not partisan and focused to achieve medium income community through skill development. The promoters strongly support national agenda of vision 2040. In fact establishing a University Project will be taken as affirmative action to the people of Kasese and entire Rwenzori 
region after all those conflicts and shocks that have traumatized the people in their history will be addressed through research and annual dissemination conferences.

\section{Way forward for progress in the Rwenzori region}

The community of Rwenzori has been divided along cultural institutions, land issues, employment opportunities, that now all these are associated to leadership of "divide and rule", that result into political disorientation hence conflicts and bloodshed.

We anticipate the following from the government or well wishes to support this project and help in community mobilization towards strengthening security, peace and good governance

i. Securing University land on which Main Campus can be established. We have earmarked Government lands that can be offered to this institution such as Bugoye County Headquarters, Part of Mubuku Prisons' Land, and Part ofMubuku Forest Reserve all in Busongora North. Another government Land is former Bukonzo County Head Quarters in Bukonzo EastConstituency. The reason why Kasese got prisons was because of Bakonzo had become "stubborn" against Toro leadership and Central Government. Hon. EzironMbette applied for these prisons since Bakonzo could be imprisoned in Katojo (Kabarole) which was not accessible the remedy was to bring prisons within reach. It is our prayer that one of the prisons' land be given to the University project to fight ignorance and train people for skills in production.

ii. Financial support as initial capital to help in constructing the first classroom buildings for this university to start with

iii. Vehicles like school lorry, a tractor machine with farm implements since the University is of Agriculture, Environment Science Management\& Technology, and means of transport for university administration.

iv. A number of Computers (100 PCs) to be used by university students and training short courses to community youth so as to engage them in technology other than useless activities

v. Linking the University to international donors like World Bank and others for development this will help it to secure initial investment capital of USA \$29 Million. As indicated in its Resources mobilization strategy (2015-2019 page 8/28). A copy provided to you.

vi. Recommending the University Project to achieve affiliation with existing and chartered universities in Uganda and other universities outside Uganda so that it can be mentored in its early stages. For instance RHU would like to have affiliation to Mbarara University of Science and Technology and Kyambogo University. ${ }^{6}$

vii. We request that soon after meeting the Honorable Minister another Meeting be arranged to meet the President on the same University Project in the Rwenzori. The proposed meeting of the promoters with the Honorable Minister of Education would lead a peaceful dialogue with the President of Uganda. This was anticipated to be a new chapter for Rwenzori region to have peace and reconciliation to enhance strengthened security, peace and good governance!
The capability of the Honarable Minister of education was underscored on her political, scientific Will, Motherly efforts displayed since 1980 and as An Educationist, the promoters of RHU were convinced that she would help them to succeed in establishing university project. As earlier mentioned the Minister have remarkable contribution in the region like a Vehicle to Rwesande Health Unit under UWESO program. The community still remembers her visit and contribution to the health centre especially maternity section as she donated a vehicle during Hon. Loice Biira Bwambale District Woman MP who is now the chairperson of the Promoters of this university project.

\section{Conclusion}

\section{Taking a lesson from polygon peace theory for conflicted region management:}

This theory is taking a mathematical logic of calculating area of polygon as proposed by Antiphons and his companion Bryson of Heraclea, the Greek Philosopher and one of the ten attic orators recognized in "Alexandria canon of ten" as orators and logographers, the affordable University Education promotion will attract back people to strengthened security, peace building and good governance. The brief explanation may provide lessons for handling issues in Rwenzori conflict prone region. The polygon is about the flat (geometrical) shapes that have got many sides of straight lines usually five or more segments joined together at angles hence its area can easily be calculated. Antiphon a Greek philosopher calculated its area by considering its upper and lower boundary. Solving the problem is about understanding what it measures. The area of a polygon can best be found by inscribing and circumscribing the polygon they postulated. The area of a polygon seems not clear hence squaring circles was theorized by the philosophers. The consequences of direct calculation without logic do not apply in all problems. The global perspective has to be put into consideration as decision is taken for problem solving. This is common in families sometimes mothers do not act quickly because they think of the family responsibility and dignity. Many of process in nature may take chaos theory or dynamic systems theory. The social scientists can as well study the Rwenzori situation under grievance theory rather than greed theory. Grievance theory as presented by Paul Collier of world Bank and Anke Hoeffler of centre for study of African economics is good for reference. These agree that greed theory apply where individual(s) finance rebellion with intend to benefit. The grievance theory applies where ethnic differences, religious divisions, political repression and inequality exist yielding to conflicts. The grievance theory apply for Rwenzori since there is nobody identified to be financing conflicts in Rwenzori rather than grieved individual coming and launch a rebellion against hegemony. Peace and security restoration do not take the same means such as military option and ideological counter attacks. Research has to be engaged during decision-making to end conflicts. ${ }^{7}$

Mathematics has been used to help and improve decision-making process in many organizations and institutions. For instance statistics theory has helped leaders in minimizing risks, establishing parameters estimations, hypothesis testing, and selecting the best option has been done. What theory have we established for the Rwenzori conflict since it can as well as be traced from 1250AD? Through current records it can still be traced from 1833AD. During the NRM regime it can still be studied and a solution established with evidence from scholarly point of view. However, this is tricky how protected will the 
researcher be if it is not sponsored by government in agreement with Obusinga Bwa Rwenzururu administration. The problem cannot be studied wholesomely because it is huge it requires narrow topics to be studied at a time. The argument is that inscribing and circumscribing the polygon was thought by the Antiphons a Greek philosopher as a solution to establish the area of polygon! If a measure or formulae is not in place then a problem cannot be solved. Ordinary people may not understand the problem of Rwenzori region which has got a far back history before the coming of colonialists in Uganda. All regimes in Uganda since 1954 have used military option in solving the conflicts in Rwenzori and it has not solved the problem as expected. Attempts of peaceful means have been tried and yield some fruits (Stacey, 2003). While dialogue is being planned to restore peace in the region, as a mother, intervention in education promotion is another solution to the problem since mothers have a strong relationship with their children. "Be more careful in guarding against censure than against danger; for the wicked may well dread the end of life, but good men (male and female) should dread ignominy during life. Strive by all means to live in security, but if ever it falls to your lot to face the dangers of battle, seek to preserve your life, but with honour and not with disgrace; for death is the sentence which fate has passed on all mankind, but to die nobly is the special honour with nature has reserved for the good" (Isocrates 436-338 BC verse 43).

Finally, developing a polygon peace theory for managing conflicted regions can be enhanced through your office as you support RHU project and research since the (RHU) philosophy is all about being; the leading university in scientific research in Africa. Why shouldn't this start with peace mission that will apply polygon peace theory? As an educationist I believe you will participate in this study which is exploratory study in nature. The assumptions for the polygon peace theory as postulated by the writer are;

i. The conflict resolution model in Rwenzori has got more segments joined together of different length with different sizes of angles and it is not a mystic rose!

ii. At least one of the segments is known by length and an exterior angle is possibly known to people willing to solve the problem

iii. Any attempt trying to move around the model (polygon) without studying each segment individuals put the expert at risk to error with the polygon's stability

iv. Inside the polygon the area is occupied by occupants that are not aware of external competing factors

v. Tracing originality of segments that constitute the polygon is reasonably valid for the determination of the area covered by the polygon.

vi. Alternatively measuring interior or exterior angles of the polygon is important in determining the area covered by the polygon

vii. Inscribing or subscribing the polygon either approach can but possibly does not find exact area of the polygon with easy hence sine and cosines has to be applied as one side possibly is known.

Mobilizing every Ugandan for education, development will be a new approach or alliance to win partisan politicians, "terrorists" and war lords in this country. The lesson got from soldiers of fortune 500 (USA) where government lend (loaned) its individuals 3:1 and increased to $4: 1$ into investment with promise to take risk into a promising venture can still apply to the Rwenzori region by establishing a local University and support community initiated projects to replace or move a long side with wealth creation programme as requested for by the community. ${ }^{5}$ The question remains what is Uganda's National policy on security when people in Rwenzori have on many occasions been killed with help of central government forces? How best can the people enjoy national security? Tracing back the major segments that were outlined by Isaaya Mukirania to be part of polygon peace segments is the model and solution to the problem. ${ }^{8,9}$

\section{Acknowledgment}

The RHU project promoters, RDC of Kasese Mr. James Mwesigye, community leaders in the region, scholars of different universities that have creatively written about Rwenzori region.

\section{Conflicts of interest}

No conflict of interest! The author has lived within and outside the region and has a story to tell in utilizing polygon peace theory.

\section{References}

1. Bamusede BB. The Faces of the Rwenzururu Movement. Kasese: Triple B. 2000.

2. Stacey T. The Tribe. The hidden History of the Mountains of the Moon. Londo: Biddles ltd. 2003.

3. Hanrahan V, Porkess R, Secker P. Pure Mathematics 1 MEI Structured Mathematics. $2^{\text {nd }} \quad$ Edition. London. JW Arrow smiths ltd. 2000.

4. Buchanan L, Gaulter B. Mathematics for GNVQ +GCSE. Oxford: Oxford University Press. 1998.

5. Howard RD, Sawyer RL. Terrorism and Counter terrorism. Understanding the New Security environment. New York: McGraw-Hill Companies. 2002 .

6. Kyambogo University. Strategic Plan 2007/08-2011/12 (Draft). Kampala. 2007.

7. Collier P, Hoeffler. Greed and Grievance theory in civil War. CSAE WPS 2002-01. 2002

8. Aquino SB. National Security Policy. Security Gains of Democracy (2011-2016). Benigno S Aquino III President of Philippines. 2010.

9. Deininger K, Castignini R. Incidence and Impact of Land conflicts in Uganda. Journal of Economic Behavior \& Organization. 2006;60(3):321-345. 